Revista Brasileira de Cartografia

ISSN 1808-0936 | https://doi.org/10.14393/revbrascartogr

Sociedade Brasileira de Cartografia, Geodésia, Fotogrametria e Sensoriamento Remoto

\title{
Percepção dos Usuários Quanto à Avaliação Indireta da Qualidade de Conjuntos de Dados Geoespaciais
}

\author{
How do users deal with the indirect evaluation of geospatial data sets quality
}

Taís Virgínia Gottardo ${ }^{1}$ e Ivanildo Barbosa ${ }^{2}$

1 Instituto Brasileiro de Geografia e Estatística, Diretoria de Geociências, Rio de Janeiro, Brasil. tais.gottardo@ibge.gov.br ORCID: https://orcid.org/0000-0003-4234-8569

2 Instituto Militar de Engenharia, Seção de Ensino de Engenharia Cartográfica, Rio de Janeiro, Brasil. ivanildo@ime.eb.br ORCID: https://orcid.org/0000-0003-4164-0875

\begin{abstract}
Resumo: A crescente disseminação de conjuntos de dados geoespaciais (CDG) por meio de serviços Web viabilizou o acesso a conteúdo cuja existência era, na maioria das vezes, desconhecida ou restrita a profissionais especializados. Com a implementação de serviços de catálogos Web (Catalog Services for Web - CSW), os metadados são preenchidos e disponibilizados de forma estruturada, facilitando a consulta por parte dos usuários aos repositórios de Infraestruturas de Dados Espaciais (IDE) e o acesso aos CDG disponibilizados. Elementos de metadados relacionados à qualidade podem auxiliar os usuários a decidir quanto à adequação do CDG à sua aplicação, seja por meio da avaliação direta dos relatórios de elementos de qualidade ou por meio de avaliação indireta baseada em outros elementos, que depende da experiência do usuário e do domínio de aplicação dos dados. Consequentemente, a avaliação da qualidade deixa de avaliar valores objetivos e definidos para considerar conceitos propensos a algum nível de subjetividade no preenchimento. O objetivo deste trabalho é identificar quais elementos de metadados remetem ao conceito de qualidade de dados geoespaciais, podendo ser usados para subsidiar o processo de avaliação indireta de qualidade. Foram avaliados os elementos Objetivo, Declaração da Linhagem, Etapas de Produção, Insumos e Nome da Organização, empregando o processo analítico hierárquico (AHP) sobre respostas de usuários com diferentes perfis. Resultados preliminares destacam a importância dos elementos de metadados Etapas de Produção, Insumos e Objetivo.
\end{abstract}

Palavras-chave: Metadados Geoespaciais. Qualidade de Dados. AHP. Linhagem. Reputação.

\begin{abstract}
The increasing availability of geospatial datasets throughout Web services granted access to content that users considered inexistent as well as restricted to specific personnel. With Catalog Services for Web (CSW), metadata are documented and distributed according to well-known specified structures, supporting users in querying Spatial Data Infrastructures' (SDI) repositories to reach the required resource. Data quality metadata elements carry useful information to assess the fitness of a dataset to a particular application either by evaluating data quality reports or by performing an indirect evaluation, based on the user's previous experiences as well as on the application domain. Consequently, quality assessment is not based on well-known objective indicators and considers parameters subject to some level of uncertainty while filling such content. This paper aims at identifying which metadata elements carry the implicit sense of quality for geospatial resources, useful to subsidize the indirect quality evaluation process. Different kinds of users answered a questionnaire regarding their impressions about the metadata elements Purpose, Statement, Process Steps, Sources, and Organization Name to provide the input for the Analytical Hierarchy Process. Preliminary results highlight the relevance of filling Process Steps, Sources and Purpose metadata elements.
\end{abstract}

Keywords: Geospatial Metadata. Data Quality. AHP. Lineage. Reputation.

\section{INTRODUÇÃO}

As Infraestruturas de Dados Espaciais (IDE) exerceram um papel relevante na ordenação da produção de dados geoespaciais e seus respectivos metadados, assim como tornou acessíveis produtos muitas vezes considerados inexistentes por seus potenciais usuários. Os serviços padronizados de catálogos Web (Catalog Services for Web-CSW) facilitam a descoberta e o acesso por parte dos usuários aos repositórios de IDE que 
armazenam recusos geoespaciais (por exemplo, conjuntos de dados geoespaciais, imagens ou serviços), quando o metadado é corretamente fornecido.

Em normas específicas que definem uma estruturação para os metadados, o tipo de preenchimento indicado para diversos elementos é o texto livre, o que pode oportunizar subjetividades relacionadas à experiência do responsável pelo preenchimento. Além disso, há diversos elementos considerados opcionais, cujo preenchimento é, muitas vezes, preterido, deixando de agregar informações que poderiam ser úteis para auxiliar o usuário na decisão sobre usar ou rejeitar um CDG catalogado.

No caso de dados geoespaciais, as medidas documentadas nos relatórios de elementos de qualidade (Consistência lógica, Completude, Usabilidade e Acurácias Temática, Posicional e Temporal) fornecem a ordem de grandeza dos elementos especificados em ISO (2013). Entretanto, Comber et al. (2006) afirmam que a maioria dos usuários não é capaz de julgar corretamente a aplicabilidade de tais resultados às aplicações enquanto Ariza-López et al. (2020) apontam uma "imaturidade" no tocante à qualidade, implicando uma baixa demanda sobre indicadores de qualidade, e a tolerância à falta desses indicadores em troca de usabilidade e qualidade de serviços. No Brasil, mais de uma década após o estabelecimento legal da Infraestrutura Nacional de Dados Espaciais (INDE) e do Perfil de Metadados Geoespaciais Brasileiro (PMGB), a documentação de relatórios de qualidade de dados geoespaciais ainda é negligenciada. A publicação de bibliografia por instituições nacionais tem facilitado a compreensão do significado dos elementos de qualidade e indicado formas de medi-los e compreendê-los (DCT, 2016; IBGE, 2019).

Uma vez que o PMGB aponta como opcional o preenchimento dos relatórios dos elementos de qualidade, muitos produtores deixam de documentá-los. Sendo assim, a oportunidade da avaliação de qualidade pelos usuários fica restrita a critérios dependentes de sua experiência e do domínio de aplicação dos dados, apresentado em ISO (2013) como avaliação indireta. Consequentemente, a análise deixa de avaliar valores objetivos e definidos para considerar conceitos propensos a algum nível de subjetividade no preenchimento.

Algumas hipóteses podem ser propostas sobre o tema:

a) a avaliação indireta é preferível à avaliação direta;

b) usuários de diferentes perfis possuem percepções diferentes sobre qualidade;

c) os usuários preferem conjuntos de metadados com mais elementos de metadados preenchidos;

Neste contexto, o objetivo deste trabalho é identificar, a partir de um grupo selecionado de elementos de metadados, quais destes remetem ao conceito de qualidade de dados geoespaciais, podendo ser usados para subsidiar a avaliação indireta dos mesmos. Com esse resultado, espera-se elencar diretrizes que otimizem o preenchimento de metadados geoespaciais de modo a comunicar ao usuário o nível de qualidade que ele pode esperar de um CDG por meio de avaliação indireta.

Após esta introdução, a seção 2 retoma conceitos sobre metadados e apresenta trabalhos relacionados. A seção 3 descreve a metodologia empregada enquanto a seção 4 apresenta os resultados obtidos. A seção 5 conclui o trabalho, com indicação de aplicações e oportunidades de continuidade.

\section{REVISÃO CONCEITUAL}

\subsection{Percepção de Qualidade}

O conceito de qualidade pode ser enunciado de diversas formas, porém todas convergem para a satisfação das expectativas dos seus usuários (ROCHA; GOMES, 1993). A busca pela satisfação dos usuários implicou estudos para aperfeiçoamento na prestação de serviços (GRÖNROOS, 2009; HOFFMANN, 2006) e na geração de dados (KLEIN, 2001; PIPINO; LEE; WANG, 2002). Entretanto, o julgamento dos critérios de satisfação é influenciado por fatores emocionais e necessidades pessoais, de modo que a qualidade do serviço prestado (do ponto de vista do produtor, seguindo especificações técnicas próprias do produto ou serviço) deve estar alinhada à qualidade percebida pelo usuário.

Strong, Lee e Wang (1997) apresentam um conjunto composto por 15 critérios a serem adotados em diversos trabalhos relacionados para avaliar a percepção de qualidade de dados: Acurácia, Objetividade, 
Credibilidade, Reputação, Acessibilidade, Segurança de acesso, Relevância, Agregação de Valor, Tempestividade, Completude, Quantidade de Dados Apropriada, Interpretabilidade, Facilidade de Compreensão, Representação Concisa, e Representação Consistente. Pipino, Lee e Wang (2002) estendem o conjunto, adicionando o critério de facilidade de manipulação para indicar se o dado pode ser empregado em diferentes aplicações.

Em Masó e Bastin (2016) é proposto um modelo conceitual para que o usuário possa se pronunciar quanto à sua percepção quanto à qualidade dos dados geoespaciais, empregando métricas de classificação (rating) como a numérica (de 1 a 5 , sendo 5 o valor atribuído à maior satisfação do avaliador), booleana ("polegar para cima" ou "polegar para baixo") ou baseada no sinal algébrico (positiva, negativa ou neutra). Essa classificação não é computada a partir de avaliações parciais mas é atribuída sumariamente pelo usuário de forma subjetiva. O resumo de avaliações fornecidas pelos usuários (média, contagem, comentários, entre outros) reflete a percepção de qualidade com base na experiência dos usuários com o CDG disponibilizado.

\subsection{Qualidade de Dados Geoespaciais}

O contexto abordado em ISO (2013) vislumbra a proposição de indicadores numéricos e não numéricos com a finalidade de permitir a comparação entre conjuntos de dados e avaliar a adequação desses aos requisitos do usuário. Os relatórios de qualidade apresentam os valores obtidos para as medidas referentes aos elementos de qualidade especificados: Completude, Consistência Lógica, Acurácias Temática, Posicional e Temporal, e Usabilidade.

Por outro lado, a avaliação de qualidade indireta se baseia em conhecimento externo ou experiência pessoal do avaliador, abrindo margem à subjetividade. Exemplos de conhecimento externo citados em ISO (2013) são os elementos de metadados especificados em ISO (2003):
a) Objetivo (do pacote $M D_{-}$Identification);
b) Emprego (do pacote $M D_{-}$Usage, agregado ao pacote $M D_{-}$Identification);
c) Linhagem (agregado ao pacote $D Q \_$DataQuality).

Este último descreve as etapas de produção e os insumos empregados na elaboração do CDG catalogado, podendo ser documentados como uma declaração textual livre (elemento de metadado Statement) ou como uma combinação dos elementos Etapas de Produção (LI_ProcessStep) e Insumos (LI_Source) empregados na elaboração do dado geoespacial (ISO, 2003). He et al. (2015) atrela a definição de linhagem adotada em ISO (2013) à proveniência do dado. Yue et al. (2015) estende esse escopo de linhagem de modo a incluir algoritmos, ambiente de processamento e a organização responsável, etre outros fatores. Eles também destacam as iniciativas de rastramento do histórico dos produtos usados em serviços e aplicações.

A avaliação de qualidade consistirá no julgamento por parte do conhecimento do usuário da robustez do processo produtivo descrito e da qualidade dos dados geoespaciais empregados na construção do dado a que se refere o metadado. Lush, Bastin e Lumsden (2012) enfatizaram a necessidade da correta documentação de linhagem com base nos levantamentos realizados com produtores e usuários de dados geoespaciais, enfatizando a metodologia de aquisição de insumos, modelo de transformação de dados, o propósito da elaboração do produto além de citações, ou seja, pessoas que tenham empregado os dados em outras aplicações. Senaratne et al. (2016) identificou 7 medidas (padronizadas e passíveis de comparação com dados de referência) e 10 indicadores (quantitativos que não podem ser comparados com fontes oficiais) em 56 artigos relacionados à qualidade da informação geográfica voluntária (Volunteered Geographic Information - VGI). Mesmo previstos em ISO (2013), foram considerados indicadores de qualidade os elementos Objetivo, Emprego e Linhagem, somados aos conceitos de confiabilidade, credibilidade e reputação do contribuidor, entre outros. Fogliaroni, D`Antonio e Clementini (2018) listam alguns trabalhos associados à avaliação de qualidade de informação geográfica voluntária, abordando métricas especificadas em ISO (2013) além de indicadores como confiança, credibilidade e reputação. A ontologia de metadados centrados no usuário proposta por Ziaimatin, Nili e Barros (2020) baseou-se na análise da percepção de usuários quanto a requisitos de adequação ao uso, abrangendo elementos de qualidade como acurácia temática, posicional e temporal e completude, assim como aspectos informacionais tais quais como perfil do produtor, descrições textuais feitas 
pelo usuário (propósito e declaração da linhagem) e informação quantitativa de qualidade. Wentz e Shimizu (2018) propõem uma metodologia de avaliação de qualidade de dados geoespaciais baseada na tomada de decisão multicritério, adotando como critérios elementos de qualidade como acurácias posicional e temporal, linhagem e extensão espacial dos CDG.

No contexto do Perfil de Metadados Geoespaciais Brasileiro (CONCAR, 2010), são especificados os metadados Declaração, Fonte dos Dados, Etapas do Processo e Objetivo. Não foi especificado o metadado para registro do Emprego.

\subsection{Reputação}

Uma das definições apresentadas por Josang, Ismail e Boyd (2007, p. 620) para reputação é "a informação normalmente dita ou crível sobre as características de uma pessoa ou coisa e seus estados". Strong, Lee e Wang (1997) correlacionam a reputação dos dados à sua acurácia e à agregação de valor, implicando em maior ou menor uso dos dados. Eles também citam a subjetividade no processo de produção, que impacta a objetividade e degrada a reputação. Essa abordagem, como tratado na seção 2.1, considera a reputação apenas do CDG em conjunto com os demais 14 critérios.

Apesar de não ter sido sugerida explicitamente entre os insumos para avaliação indireta de qualidade, a reputação do produtor do dado geoespacial foi citada em Barbosa e Casanova (2011) e por Lush, Bastin e Lumsden (2012) como um fator relevante na decisão sobre usar ou rejeitar um conjunto de dados.

Cabe ressaltar que reputação não implica confiança, isto é, um usuário pode não confiar no dado disponibilizado por um produtor de boa reputação, assim como pode confiar em um conjunto de dados mesmo que o produtor ainda não possua boa reputação. Esse fator ganha relevância quando se discute o crescimento de iniciativas voluntárias e colaborativas para aquisição de dados temáticos e de referência.

Gusmini et al. (2017) argumentam que a VGI permite produzir conteúdo atual, tempestivo e detalhado em situações em que dados oficiais não estão disponíveis, além de defender que o conteúdo produzido captura diferentes perspectivas a partir da percepção de um universo heterogêneo de usuários. Em contrapartida, reconhece que a VGI é heterogênea em cobertura, densidade e qualidade, razão pela qual propõem um modelo e uma arquitetura para avaliar a reputação dos contribuidores da VGI. A reputação também é mencionada em Senaratne et al. (2016), em Fogliaroni, D’Antonio e Clementini (2018), em Degrossi et al. (2018) e em Moreri, Fairbairn e Philip James (2018).

Não existe qualquer campo explícito em ISO (2003), ISO (2013) ou CONCAR (2010) para documentar a reputação, mas a experiência do usuário, direta ou recomendada, associa a organização produtora à qualidade dos dados produzidos.

\subsection{Processo Hierárquico Analítico}

O Processo Hierárquico Analítico - em inglês, Analytic Hierarchy Process (AHP), é apresentado em Saaty (1983) como um recurso para auxiliar na tomada de decisão baseada em análise multicritério. Essa abordagem consiste na decomposição do problema em partes menores, comparando-as em pares com o intuito de eleger prioridades em cada hierarquia. A hierarquia consiste na subdivisão dessas partes em partes ainda menores.

A etapa de julgamentos paritários - terminologia empregada por Marins, Souza e Barros (2009), define a relação de dominância entre as variáveis comparadas na forma de matrizes de julgamento. Se o elemento A domina o elemento $\mathrm{B}$, associa-se um número inteiro $n$ é inserido na linha $\mathrm{A}$ e coluna $\mathrm{B}$ e o inverso desse número $(1 / n)$ na linha $\mathrm{B}$, coluna $\mathrm{A}$; se o elemento $\mathrm{B}$ domina o elemento $\mathrm{A}$, o preenchimento da matriz de comparação ocorre da forma inversa. Os valores inteiros variam de 1 a 9 , crescendo conforme cresce a dominância.

A consistência do preenchimento da matriz de julgamento é verificada por meio da Razão de Consistência (RC) e do Índice de Consistência (IC), conforme Marins, Souza e Barros (2009). A consistência medida verifica se houve, na composição da matriz de julgamentos paritários $\mathrm{A}$, violações numéricas $\left(a_{i j} a_{j k}=\right.$ $\left.a_{i k}\right)$ e transicionais, ou seja, na ordem das hierarquias. Tais índices refletem o quanto os julgamentos realizados 
em pares são consistentes, permitindo escalonar adequadamente as prioridades. Consideram-se consistentes as matrizes cuja RC seja inferior a $10 \%$. Caso a matriz de julgamentos leve a valores superiores, os valores inseridos na matriz A precisam ser revistos. Saaty (1983) ressalta a dificuldade de obter perfeição na consistência dos valores medidos.

O vetor de prioridades é calculado a partir da matriz de julgamentos, fornecendo a prioridade relativa entre os critérios considerados no processo a partir do maior autovalor da matriz de julgamento. Esse vetor é empregado na ponderação das alternativas a fim de indicar a mais vantajosa, auxiliando assim o processo decisório.

O AHP é um método consolidado de tomada de decisão multicritério amplamente utilizado no setor público, privado e por pesquisadores. Em 2001, mais de 1000 artigos e quase 100 dissertações de doutorado que utilizavam AHP estavam disponibilizadas no portal Expert Choice (FORMAN e GASS, 2001). Vaidya e Kumar (2006) apresentam uma análise de 150 artigos publicados em jornais de relevância científica, que utilizaram AHP como apoio a tomada de decisão em problemas complexos em aplicações sociais, políticas, de engenharia, da indústria, entre outras. Sipahi e Timor (2010) realizaram uma revisão bibliográfica das aplicações de AHP a partir de 169 artigos publicados em periódicos acadêmicos internacionais de grande renome, no período entre 2005 e 2009, identificando o uso do AHP como uma ferramenta de decisão gerencial para, por exemplo, avaliação de estratégia, avaliação de desempenho, projeto de produto e processo, avaliação de qualidade e medição de objetivos. Ao pesquisar a aplicação do AHP para tomada de decisões, especificamente para a área de sustentabilidade, dos Santos et al. (2019), abordaram 173 manuscritos publicados entre 2014 e 2018, indexados pelas bases de dados Web of Science, Scopus e Science Direct.

\section{METODOLOGIA}

O objetivo proposto - identificar quais elementos de metadados remetem ao conceito de qualidade de dados geoespaciais - pode ser abordado de diferentes maneiras, tendo em vista a subjetividade inerente à avaliação indireta. A abordagem adotada neste trabalho consistiu em a) identificar quais elementos de metadados são fundamentais para subsidiar o julgamento da qualidade pelo usuário e b) investigar a eventual relação hierárquica de preferência por parte dos usuários entre esses metadados.

A metodologia empregada para essa finalidade foi dividida em 6 fases, a saber:

a) Seleção dos elementos de metadados;

b) elaboração de questionário;

c) avaliação do perfil dos respondentes;

d) avaliação da necessidade de preenchimento dos elementos isoladamente;

e) identificação da prioridade dos critérios;

f) interpretação dos resultados.

\subsection{Seleção dos Elementos de Metadados}

O cenário a ser abordado parte da premissa que o usuário possui somente os metadados, sem ter acesso aos relatórios de elementos de qualidade nem aos respectivos arquivos. Isso distingue o intuito deste trabalho do conceito de percepção de qualidade, pois a percepção de qualidade normalmente está associada à satisfação do usuário após comparar o dado fornecido com as suas expectativas pessoais.

Neste contexto, foram selecionados os metadados Objetivo, Declaração de Linhagem, Etapas de Produção e Insumos, sugeridos em ISO (2013) e especificados em CONCAR (2010) por remeterem a conceitos de qualidade de dados capazes de serem empregados antes mesmo de o usuário acessar o CDG de interesse.

\subsection{Elaboração de Questionário}

O questionário foi concebido a fim de coletar as opiniões dos usuários quanto a dois aspectos: o primeiro se refere à necessidade do preenchimento dos elementos de metadados, refletindo a importância dada 
pelo usuário no processo de avaliação indireta de qualidade; o segundo se refere à identificação de uma possível dominância entre os elementos avaliados, refletindo a preferência do usuário por um elemento em detrimento ao outro.

Também foram solicitadas informações sobre o perfil dos respondentes quanto ao seu conhecimento sobre metadados e sobre avaliação de qualidade de dados geoespaciais, assim como quanto à sua ocupação (Quadro 1), visando pormenorizar a análise dos dados coletados. Também foi inserida uma breve revisão dos termos empregados ao longo do questionário, a fim de elucidar eventuais dúvidas durante o preenchimento do questionário.

As questões sobre a necessidade de preenchimento foram realizadas de forma objetiva, de modo que o respondente assinalasse, dentre as opções apresentadas no Quadro 1, qual o seu posicionamento em relação a cada um dos metadados avaliados.

As questões sobre dominância avaliaram se a substituição de um elemento de metadado seria viável no contexto da avaliação subjetiva da qualidade dos dados geoespaciais, conforme opções apresentadas no Quadro 1. Os cinco elementos de metadado avaliados foram comparados, também, com os relatórios de elementos de qualidade, a fim de avaliar a importância dada à avaliação indireta.

O questionário foi elaborado em português e em inglês, e divulgado por meio de redes sociais (grupos voltados a temas de interesse da comunidade geocientífica, no Brasil e no exterior) e mensagens eletrônicas para alunos, professores e profissionais produtores e usuários de geoinformação a partir de janeiro de 2020. A última resposta computada foi submetida em meados de março de 2020.

\subsection{Avaliação do perfil dos respondentes}

Uma das motivações deste trabalho é identificar as expectativas dos diversos tipos de usuários de CDG disponibilizados em infraestruturas de dados espaciais (IDE). Como nem todos aqueles tipos possuem formação acadêmica ou profissional que aborde diretamente os temas de qualidade de dados e metadados geoespaciais, é preciso analisar a percepção subjetiva de cada tipo a fim de direcionar o preenchimento de metadados e embasar ações de capacitação a grupos específicos.

Em um primeiro momento foram identificados quantos usuários pertencem a cada categoria funcional (usuário, produtor, professor ou pesquisador, estudante). Em seguida, os respondentes foram classificados quanto ao domínio dos conceitos sobre qualidade de dados e metadados. Tal composição pôde ajudar a entender melhor as expectativas de cada grupo de usuários.

\subsection{Avaliação da necessidade}

Esta etapa consistiu em agrupar as respostas obtidas, de acordo com as opções fornecidas (Quadro 1), a fim de quantificar como os respondentes de diferentes perfis (de ocupação) avaliam a necessidade de preenchimento dos metadados propostos para fins de avaliação indireta de qualidade.

Os percentuais de respostas necessário e desejável indicam a importância dos metadados para a avaliação indireta da qualidade, enquanto o percentual de respostas desnecessário indica que o preenchimento do metadado não interfere na avaliação da qualidade do CDG em questão. O percentual de respostas prefiro não opinar indica que a compreensão sobre o metadado, mesmo após a revisão conceitual no início do questionário, ainda é insuficiente.

\subsection{Identificação da prioridade}

O objetivo desta etapa foi calcular o vetor de prioridades com base na matriz A, de julgamentos paritários realizados pelos respondentes. A matriz de julgamentos foi preenchida com valores entre 1 e 9 no caso de dominância (A domina sobre B), e nos valores de 1 até $1 / 9$, inversos aos respectivos valores de dominância (B é dominado por A). Cabe salientar que a diagonal principal é preenchida com 1 (um), pois indica o julgamento de um metadado em comparação consigo próprio. 
Quadro 1 - Resumo do questionário empregado na metodologia

\begin{tabular}{|c|c|c|}
\hline $\begin{array}{l}\text { Aspecto } \\
\text { Avaliado }\end{array}$ & Pergunta & Opções \\
\hline \multirow{3}{*}{ Perfil do Usuário } & $\begin{array}{c}\text { Com qual das opções abaixo } \\
\text { você mais se identifica? } \\
\text { (Ocupação) }\end{array}$ & $\begin{array}{l}\text { - Sou profissional e minha atividade demanda o emprego de dados } \\
\text { geoespaciais. } \\
\text { - Sou profissional e atuo na produção de dados geoespaciais. } \\
\text { - Sou professor ou pesquisador e minha atividade demanda o emprego } \\
\text { de dados geoespaciais. } \\
\text { - Sou estudante de áreas que empregam dados geoespaciais em suas } \\
\text { aplicações. }\end{array}$ \\
\hline & $\begin{array}{l}\text { Meu conhecimento sobre } \\
\text { metadados geoespaciais é: }\end{array}$ & $\begin{array}{l}\text { - Razoável: conheço o tema, mas não uso frequentemente } \\
\text { - Domino: responderia com tranquilidade perguntas sobre as normas } \\
\text { existentes sobre o assunto } \\
\text { - Já ouvi falar sobre o assunto: com alguma recapitulação posso } \\
\text { - } \quad \text { Desponder sobre o assunto } \\
\text { - Desconheço: não me arrisco a responder o questionário }\end{array}$ \\
\hline & $\begin{array}{l}\text { Meu conhecimento sobre } \\
\text { qualidade de dados } \\
\text { geoespaciais é: }\end{array}$ & $\begin{array}{l}\text { - Razoável: conheço o tema, mas não uso frequentemente } \\
\text { - Domino: responderia com tranquilidade perguntas sobre as normas } \\
\text { existentes sobre o assunto } \\
\text { - Já ouvi falar sobre o assunto: com alguma recapitulação posso } \\
\text { - } \quad \text { Desponder sobre o assunto } \\
\text { - }\end{array}$ \\
\hline Necessidade & $\begin{array}{l}\text { Na sua opinião, para } \\
\text { avaliação da qualidade do } \\
\text { dado geoespacial, o } \\
\text { preenchimento dos seguintes } \\
\text { metadados é: }\end{array}$ & $\begin{array}{l}\text { - Prefiro não opinar } \\
\text { - Desnecessário: a informação não influencia na inferência da qualidade } \\
\text { do dado geoespacial. } \\
\text { - Desejável: a informação não é o fator mais importante na inferência da } \\
\text { qualidade do dado geoespacial, mas pode ajudar a decidir. } \\
\text { - Necessário: a informação é determinante na inferência da qualidade do } \\
\text { dado geoespacial. }\end{array}$ \\
\hline Prioridade & $\begin{array}{c}\text { O metadado A poderia ser } \\
\text { substituído pelo metadado B? }\end{array}$ & $\begin{array}{l}\text { - } \quad \text { Prefiro não opinar } \\
\text { Discordo completamente: a substituição prejudica o julgamento da } \\
\text { qualidade do CDG. } \\
\text { - Ambos são igualmente importantes: a substituição não favorece ou } \\
\text { prejudica o julgamento da qualidade do CDG. } \\
\text { - Os conteúdos são complementares: as informações combinadas } \\
\text { favorecem o julgamento da qualidade do CDG. } \\
\text { - Concordo completamente: a substituição favorece o julgamento da } \\
\text { qualidade do CDG. }\end{array}$ \\
\hline $\begin{array}{l}\text { País (apenas na } \\
\text { versão } \\
\text { internacional) }\end{array}$ & $\begin{array}{c}\text { Please inform the country you } \\
\text { live in }\end{array}$ & Livre \\
\hline
\end{tabular}

Fonte: Os autores (2021).

Para obter os elementos $A_{j k}$ da matriz de julgamentos paritários, cujos valores variam entre $1 / 9$ e 9 , foi empregada a Eq. (1).

$$
A_{j k}=9 \frac{D-C}{D+C+C C+1}
$$

onde:

- $D$ é a quantidade de respostas discordo completamente e indica que o elemento de metadado da linha $j$ é mais relevante do que o elemento da coluna $k$ );

- $\quad C$ é a quantidade de respostas concordo completamente e indica que o elemento da coluna $k$ pode substituir o elemento da linha $j$;

- I é a quantidade de respostas ambos são igualmente importantes, ou seja, pode-se usar um ou outro;

- $C c$ é a quantidade de respostas os conteúdos são complementares, ou seja, ambos são necessários em conjunto.

Cabe ressaltar que os valores $I$ e $C c$ indicam o equilíbrio entre os elementos da linha $j$ e da coluna $k$. 
O total de respostas referentes à opção prefiro não opinar não foi considerado por caracterizar que o respondente se absteve de seu julgamento.

A adoção da função exponencial se deve à associação direta de valores entre $1 / 9$ e 9 , domínio dos valores de julgamentos. Uma eventual desvantagem é o rápido decréscimo da função decorrente de uma resposta de peso neutro ou negativo. Para ilustrar, o valor de $A_{j k}$ será 9 se todas as respostas forem discordo completamente (expoente igual a 1), mas será 8,06 se o expoente for igual a 0,95 e igual a 3 se o expoente for igual a 0,5 . Consequentemente, os resultados serão fortemente influenciados pelas alternativas que indicam o equilíbrio entre os metadados. Uma solução para minimizar esse efeito, pode-se empregar a Eq. (2), adaptada da Eq. (1), ponderando as respostas concordo completamente e discordo completamente ao atribuir valores inteiros positivos ao fator $n$ (a Eq. (1) é um caso particular em que $n=1$ ).

$$
A_{j k}=9^{\frac{n(D-C)}{n(D+C)+C C+I}}
$$

Seguindo a sequência do método AHP, é necessário computar a razão de consistência da matriz de julgamentos a fim de validar os valores obtidos (MARINS; SOUZA; BARROS, 2009). São esperados valores inferiores a $10 \%$, considerando a matriz de julgamentos com dimensão seis: Objetivo, Declaração da Linhagem, Etapas de Produção, Insumos, Nome da Organização, Relatórios dos Elementos de Qualidade. Os relatórios foram inseridos para testar a hipótese de que a avaliação indireta é preferível à direta com base na prioridade dada a essa opção em relação às demais.

Com os vetores de prioridade, é possível quantificar a predominância entre elementos de metadados na forma percentual. Os valores foram computados tanto em conjunto quanto classificados pelos perfis de respondentes.

\section{RESULTADOS OBTIDOS}

\subsection{Avaliação do perfil dos respondentes}

A avaliação foi realizada com base em 49 respostas obtidas entre os meses de janeiro e março de 2020 . A síntese das estatísticas dos respondentes encontra-se na Tabela 1.

Tabela 1 - Perfil dos respondentes

\begin{tabular}{c|c|c}
\hline Aspecto avaliado & Opções & Respostas \\
\hline \multirow{2}{*}{ Metadados } & Razoável & 30 \\
Geoespaciais & Domino & 14 \\
& Já ouvi falar sobre o assunto & 5 \\
& Desconheço & 0 \\
\hline \multirow{3}{*}{ Qualidade de Dados } & Razoável & 29 \\
Geoespaciais & Domino & 13 \\
& Já ouvi falar sobre o assunto & 6 \\
\hline \multirow{3}{*}{ Atividade } & Desconheço & 1 \\
& Professor ou pesquisador & 15 \\
& Profissional cuja atividade demanda o emprego de dados geoespaciais & 15 \\
& Profissional que atua na produção de dados geoespaciais & 15 \\
\end{tabular}

Fonte: Os autores (2021).

Os dados contidos na Tabela 1 indicam que os respondentes declararam ter conhecimento suficiente para responder aos questionamentos com segurança. O respondente que declarou desconhecer o tema de qualidade de dados geoespaciais pertence ao grupo de profissionais cuja atividade demanda o emprego de dados geoespaciais.

Pôde-se observar a baixa adesão de estudantes. Em virtude da baixa adesão, essa categoria não será considerada nas análises da seção 4.3. 


\subsection{Avaliação da necessidade}

A síntese das estatísticas das respostas relacionadas a esta etapa está representada na Figura 1, incluindo a discriminação dos resultados considerando os perfis e as proporções observadas no conjunto completo de respostas: a) Objetivo; b) Declaração da Linhagem; c) Etapas de Produção; d) Insumos; e) Nome da Organização; e f) Síntese da Composição Geral.

Figura 1 - Resultados relacionados à necessidade de preenchimento de elementos de metadados.

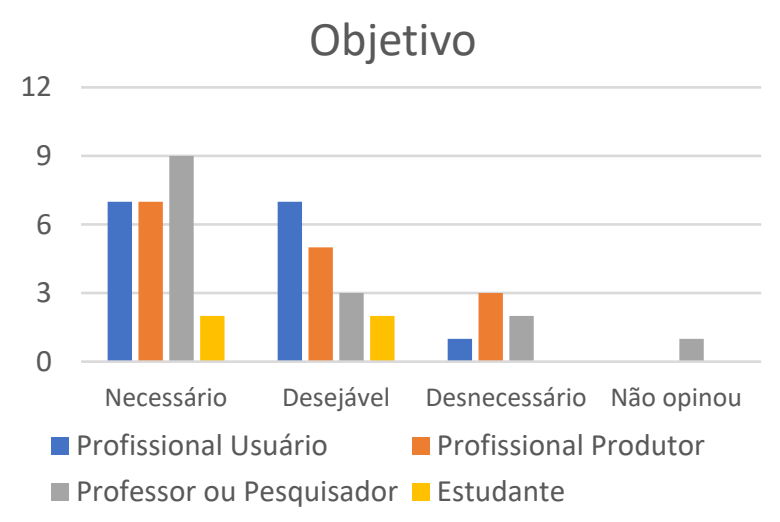

(a)

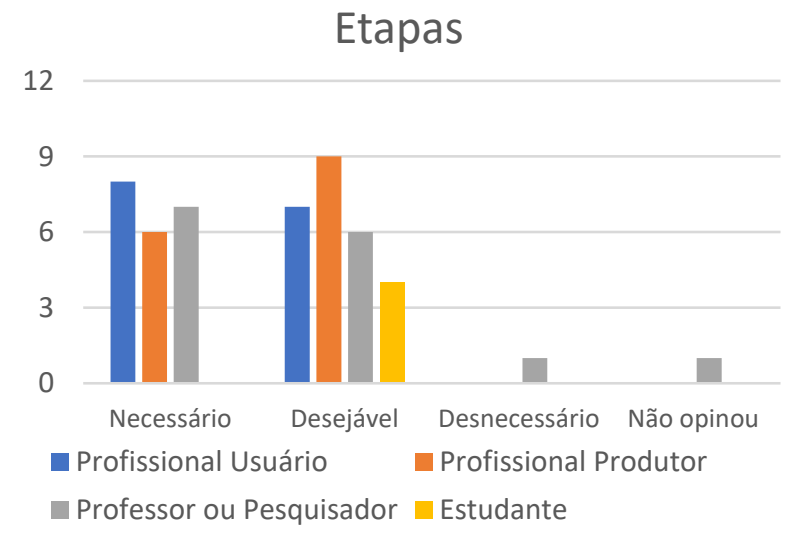

(c)

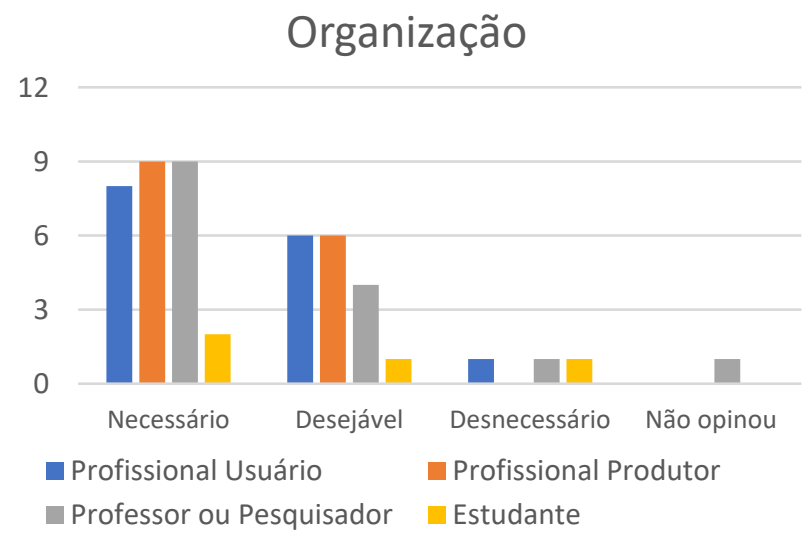

(e)

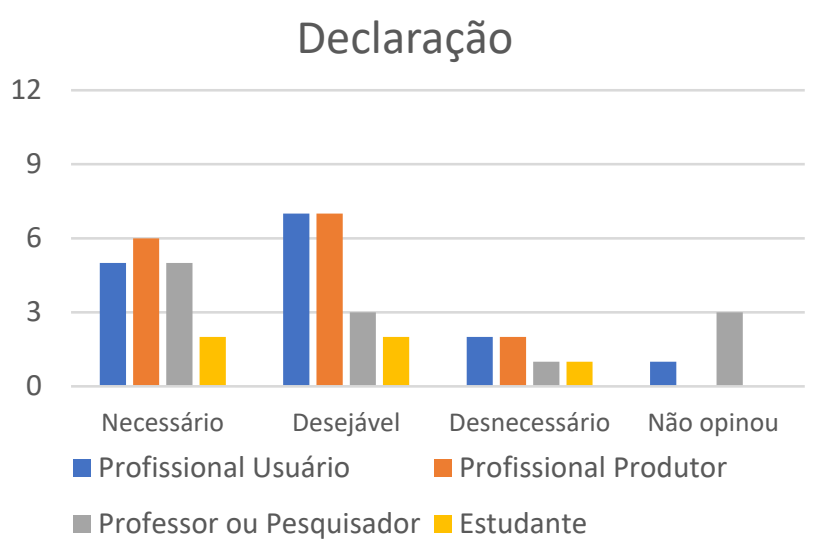

(b)

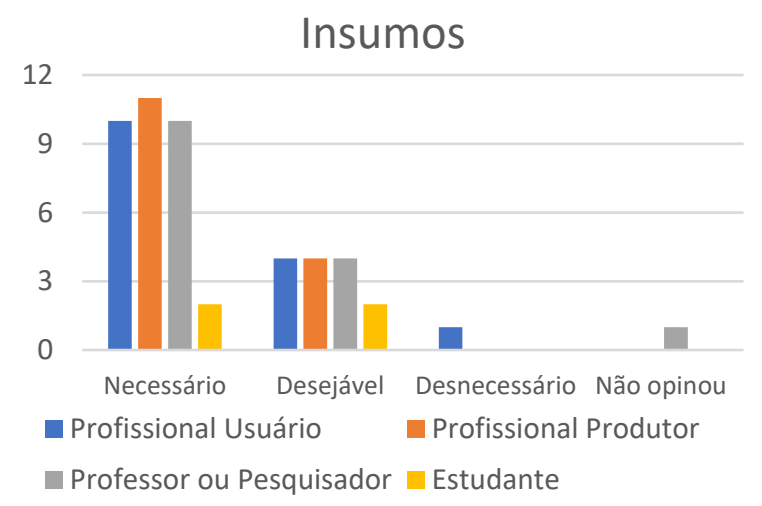

(d)

\section{Composição Geral}

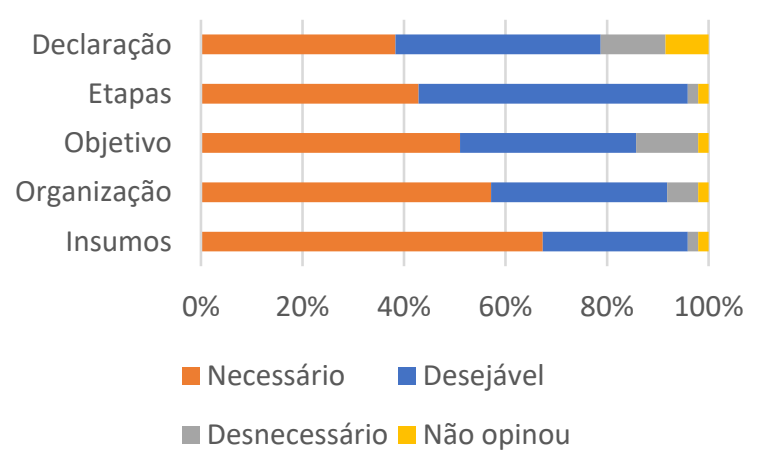

(f)

Fonte: Os autores (2021) .

O primeiro ponto a destacar é que o metadado Declaração da Linhagem, especificado como obrigatório no Perfil MGB e destinado à descrição geral sobre o conhecimento do produtor sobre o histórico de produção de um $\mathrm{CDG}$, foi considerado pelos $12 \%$ dos respondentes como desnecessário enquanto $8 \%$ não 
foi capaz de opinar (Tabela 2). Isso significa que, para a primeira parcela, uma descrição textual do histórico do dado, isoladamente, não é relevante para embasar sua avaliação de qualidade e, para a segunda parcela, predominantemente composta por professores e pesquisadores, não fica clara a relação entre o preenchimento desse elemento com a avaliação indireta de qualidade dos dados. A Figura $1 \mathrm{f}$ mostra que este elemento foi considerado necessário por menos de $40 \%$ dos respondentes, a maioria destes professores e pesquisadores.

Tabela 2 - Avaliação da necessidade dos metadados.

\begin{tabular}{c|c|c|c|c}
\hline Metadado & Necessário & Desejável & Desnecessário & Prefiro não opinar \\
\hline Objetivo & $51.02 \%$ & $34.69 \%$ & $12.24 \%$ & $2.04 \%$ \\
Declaração da Linhagem & $38.30 \%$ & $40.43 \%$ & $12.77 \%$ & $8.51 \%$ \\
Etapas de Produção & $42.86 \%$ & $53.06 \%$ & $2.04 \%$ & $2.04 \%$ \\
Insumos & $67.35 \%$ & $28.57 \%$ & $2.04 \%$ & $2.04 \%$ \\
Nome da Organização & $57.14 \%$ & $34.69 \%$ & $6.12 \%$ & $2.04 \%$ \\
\hline
\end{tabular}

Fonte: Os autores (2021).

Em contrapartida, os resultados relacionados aos elementos componentes da Linhagem, ou seja, Etapas de Produção e Insumos, foram considerados necessários ou desejáveis por mais de $95 \%$ dos respondentes. O elemento Insumos foi considerado necessário por mais de dois terços dos respondentes.

Outro ponto de destaque é alta aprovação do metadado Objetivo como metadado significativo na avaliação indireta da qualidade, uma vez que é especificado no Perfil MGB como opcional e, possivelmente, pode estar sendo negligenciado pelos produtores. Um quinto dos respondentes pertencentes ao grupo dos produtores considerou o campo desnecessário para fins de avaliação indireta da qualidade, enquanto para os usuários dos demais grupos, combinados, menos de 10\% consideram esse metadado desnecessário.

Foi identificada a relevância da influência da reputação do produtor na avaliação indireta da qualidade dos dados geoespaciais. Como se trata de metadado de preenchimento obrigatório de acordo com o perfil MGB, tal constatação não afeta a forma de preenchimento atual de metadados.

Por fim, destaca-se, também, a baixa taxa de metadados considerados desnecessários. Essa informação vai ao encontro da hipótese de que os usuários em geral preferem avaliar a qualidade de um CDG com base em um conjunto mais completo de metadados.

\subsection{Identificação da prioridade}

Após a consolidação das respostas, foram calculados os vetores de prioridades geral e classificado por perfil profissional com base na Eq. (1). Os valores exibidos no gráfico da Figura 2 representam as predominâncias calculadas considerando os Relatórios de Elementos de Qualidade, assim como os elementos Insumos, Organização, Objetivo, Etapas de Produção e Declaração. Não foram tratados individualmente nesta etapa os resultados referentes à categoria de estudantes devido à baixa adesão citada na seção 4.1. Entretanto, todas as respostas foram incluídas no resultado total.

A Figura 2 destaca a diferença nos critérios de avaliação entre os diferentes perfis de respondentes, hipótese indicada na Seção introdutória. Como os valores da matriz de julgamento foram obtidos por meio da Eq. (1), os valores indicados na figura estão sujeitos a pequenas variações, mesmo mantendo a sua consistência (Tabela 3). Entretanto, cabe salientar que as maiores divergências observadas referem-se à relevância atribuída pelos usuários aos relatórios de elementos de qualidade e ao elemento Objetivo declarado pelo produtor. 
Figura 2 - Valores obtidos nas matrizes de prioridade total e por perfil de usuários.

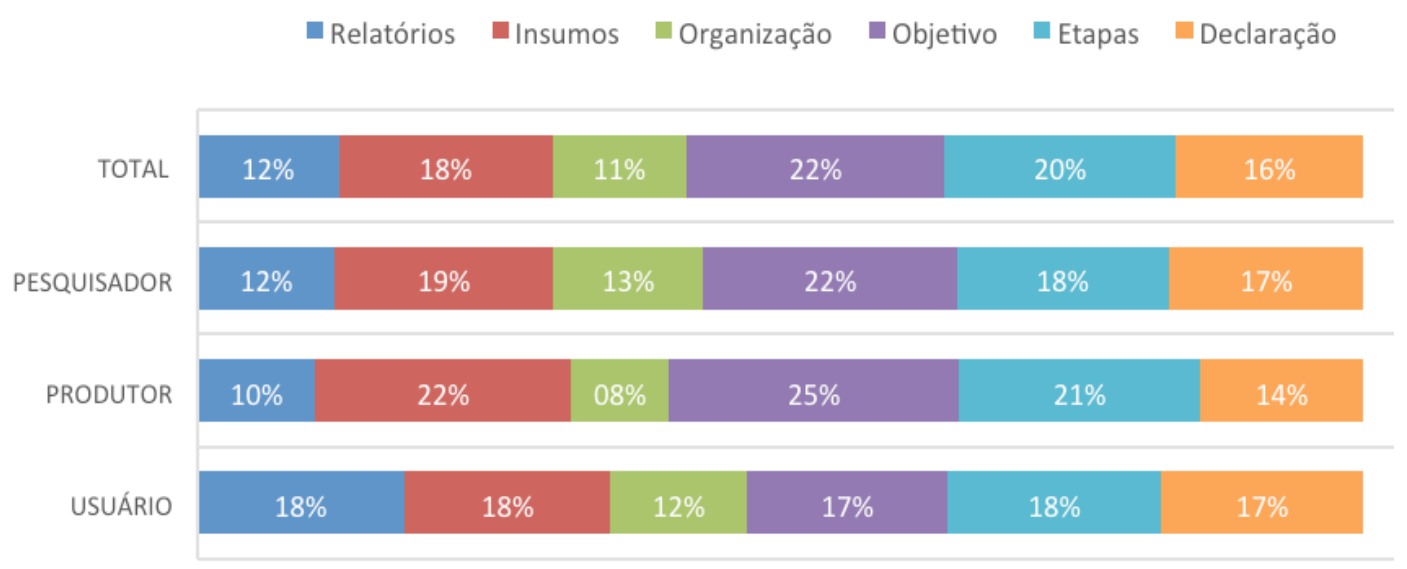

Fonte: Os autores (2021).

Para fins de validação, os valores obtidos para a razão de consistência encontram-se organizados na Tabela 3, indicando maior consistência nas respostas fornecidas pelos usuários. Entetanto, todos encontramse abaixo do valor de referência de $10 \%$, citado na seção 2.4 , reforçando que os julgamentos paritários foram adequados, mesmo que com sutis divergências quanto à cardinalidade e à ordenação dos critérios.

Tabela 3 - Razões de consistência calculados com base nas matrizes de julgamento.

\begin{tabular}{c|c|c|c|c}
\hline Critério & Usuário & Produtor & Pesquisador & Total \\
\hline Razão de Consistência & $2.51 \%$ & $6.73 \%$ & $5.8 \%$ & $4.17 \%$ \\
\hline
\end{tabular}

Fonte: Os autores (2021).

Foram calculados os vetores de prioridades totais variando o valor de $n$ entre 2 e 4 na Eq. (2), obtendo razões de consistência de $7,26 \%$ e $9,99 \%$, respectivamente. Valores de $n$ superiores a 5 tornam a razão de consistência superior a 10\%, o que invalida a análise (Seção 2.4). Os resultados não alteraram a ordem de prioridade geral observada na Figura 2, mas realçaram os valores obtidos, aumentando a diferença entre as porcentagens calculadas. Os resultados obtidos entre produtores apresentaram maiores razões de consistência, excedendo o limite de $10 \% \mathrm{com} \mathrm{n}=2$. Consequentemente, adotar a Eq. (1) para criar a matriz de julgamentos paritários é suficiente pois otimiza a razão de consistência sem distorcer a ordem de prioridade dos critérios adotados.

Considerando todos os respondentes, a relevância dos relatórios apresentou mesma ordem de grandeza da reputação da Organização. Entre professores e pesquisadores, foi o item de menor relevância. Entretanto, aparecem com alta prioridade entre os usuários não atuantes na produção e fora do meio acadêmico. Incrementando o valor de $n$ na Eq. (2), as diferenças são realçadas, elevando a prioridade atribuída aos relatórios a 19,4\% quando $n=4$, com razão de consistência de $8,1 \%$. Isso sugere que os relatórios de qualidade não podem ser negligenciados para essa categoria de usuários mas, no geral, a hipótese de que a avaliação indireta é preferível à direta pode ser confirmada.

Foi observada, também, a alta prioridade atribuída ao elemento Objetivo, mais especificamente entre produtores, professores e pesquisadores. Muito embora uma porcentagem expressiva de respondentes dessas categorias tenha classificado o metadado como desnecessário, ao comparar sua relevância com a de outros metadados, priorizou o Objetivo como critério para avaliação de qualidade. O mesmo fenômeno pode ser observado ao analisar os valores obtidos para o metadado declaração, mesmo que em menor magnitude: antes considerado desnecessário ou desconhecido por mais de $20 \%$ dos respondentes, figura com $16 \pm 2 \%$ de relevância.

Em contrapartida, identificou-se a baixa prioridade atribuída à reputação do produtor nesta etapa da análise, mesmo sendo indicada como necessária por quase $60 \%$ dos respondentes (Tabela 2). Isso sugere que a combinação com outros elementos de metadados altera a sua prioridade.

Em comum a todos esses pontos, destaca-se a heterogeneidade entre os resultados obtidos por usuários de diferentes perfis. Tais diferenças são realçadas quando o valor de n na Eq. (2) aumenta. Professores e 
Pesquisadores divergem dos Usuários em geral quanto à importância dada pelos primeiros ao elemento Objetivo enquanto o segundo grupo prioriza os Relatórios de Elementos de Qualidade. Por outro lado, são os perfis que apresentam os melhores valores de razão de consistência. Os respondentes identificados com o perfil de Produtores indicaram como prioridade os elementos relacionados à linhagem em detrimento dos elementos Organização e dos Relatórios de Elementos de Qualidade. Por outro lado, as altas razões de consistência obtidas indicam que os julgamentos em pares não foram tão coerentes quanto aqueles realizados pelos respondentes de outro perfil, tornando necessário refinar os resultados obtidos com mais respondentes.

Por fim, os resultados relacionados a Etapas de Produção e Insumos corroboram o que foi observado na seção 4.2: o correto preenchimento desses metadados fornecerá ao usuário o subsídio necessário para avaliação indireta da qualidade de dados geoespaciais.

\section{CONCLUSÕES}

O objetivo proposto para este trabalho foi identificar quais elementos de metadados remetem ao conceito de qualidade de dados geoespaciais, podendo ser usados para subsidiar a avaliação indireta dos mesmos. Foram desconsiderados aspectos que demandem o acesso e a utilização do usuário ao CDG em qualquer aplicação.

Ao avaliar a necessidade de preenchimento dos elementos de metadados selecionados, o elemento Insumos foi citado por mais de dois terços dos respondentes como necessário, enquanto um em cada oito respondentes considera desnecessário o preenchimento dos elementos Objetivo e Declaração da Linhagem. Cerca de $80 \%$ dos respondentes indicou que todos os elementos propostos como necessários ou desejáveis, indicando que os usuários preferem conjuntos de metadados com mais metadados preenchidos. Isso indica a relevância dos elementos referentes à abordagem mais ampla de provendiência dos dados, conforme Yue et al. (2015).

Os resultados de pergunta similar, porém com outras opções de critério para seleção, obtidos por Ziaimatin, Nili e Barros (2020), indicam a reputação do produtor como a maior influência sobre a avaliação de adequação ao uso. Neste trabalho, este critério foi considerado necessário ou desejável por mais $90 \%$ dos respondentes. Em contrapartida, Objetivo e Declaração de Linhagem, caracterizados como "soft knowledge", e Linhagem apresentaram menores escores de relevância, mas ainda bem acima da referência de neutralidade da escala de Likert empregada naquele trabalho. Cabe ressaltar que suas análises foram baseadas em 15 respostas, e que o percentual de produtores dentre os respondentes é de $80 \%$ (em contraponto a $30 \%$ dos respondentes deste trabalho).

A análise da precedência entre os elementos para fins de avaliação indireta de qualidade apontou os elementos Objetivo, Etapas de Produção e Insumos como os mais relevantes que os demais, inclusive os relatórios de elementos de qualidade. Isso aponta que os usuários percebem mais valor em elementos que prestam à avaliação indireta, do que em elementos que retratam a avaliação direta ou objetiva de qualidade dos dados geoespaciais.

Dentre os fatores que podem explicar tais resultados, podem ser citados o maior grau de conhecimento e domínio técnico demandado na interpretação dos relatórios, que restringe o público habilitado a interpretar as métricas e valores apresentados, assim como a disponibilização recente de publicações que apoiam a aplicação prática da norma ISO 19157 (DCT, 2016; IBGE, 2017), demandando algum tempo para capacitar e aperfeiçoar pessoal para avaliar a qualidade de dados geoespaciais e interpretar adequadamente os valores obtidos nos relatórios de elementos de qualidade - a maturidade de qualidade citada por Ariza-López et al. (2020).

Cabe salientar que os resultados obtidos foram diferentes quando comparados por perfis de usuários, destacando a discrepância na percepção entre produtores e usuários. Isso pode ser explicado pela diferença na formação acadêmica. A diferença de percepção reforça a importância de os produtores estreitarem a comunicação com os usuários a fim de compreendê-lo para melhor atendê-lo. As razões de consistência obtidas reforçam a importância de focar nas necessidades dos usuários de perfil acadêmico e geral.

Cabe, também, ressaltar que, em setembro de 2020, estavam cadastrados 38.649 metadados no repositório da INDE. Destes, apenas 22,7\% possuem os valores de Objetivo preenchidos, 13,8\% possuem 
informações sobre Insumos e $0,9 \%$ informam as Etapas de produção. Não foram analisados os conteúdos preenchidos, cujo equívoco tende a agravar ainda mais a falha na comunicação da qualidade. Os resultados obtidos neste trabalho sugerem aos produtores de dados geoespaciais que priorizem o preenchimento desses elementos em especial, a fim de melhor comunicar o conceito de qualidade para produtores, professores, estudantes e consumidores de dados geoespaciais em geral.

Os resultados alcançados nessa pesquisa decorrem de 49 respostas obtidas para o questionário aplicado. Desses respondentes, $89 \%$ e $86 \%$ declararam ter algum grau de conhecimento sobre metadados geoespaciais e qualidade de dados geoespaciais, respectivamente. Trata-se de resultado preliminar, de modo que uma quantidade maior de respostas ao questionário, preferencialmente em quantidade representativa quanto à proporcionalidade dos perfis de usuários, de certo trará à pesquisa maior grau de robustez. Entretanto, mesmo sendo um resultado preliminar, reúne opiniões de um grupo com elevado grau de especialização nos assuntos envolvidos.

Nesse contexto, os resultados obtidos remetem à reflexão por parte dos produtores de que é imprescindível que o metadado disponibilizado contemple as informações necessárias e suficientes para o adequado uso e aplicação do dado geoespacial. Somente dessa maneira os metadados cumprirão em plenitude suas diversas funções, como facilitar a investigação feita pelo usuário, evitar que usuários tenham que buscar informações extras por meios não oficiais, apoiar o correto uso do dado, garantir aplicações diversas e agregação de valor, reduzir duplos esforços, entre outros tantos benefícios que evidenciam a responsabilidade do produtor com o ciclo de vida do dado.

Pesquisas futuras podem investigar o que leva os usuários a priorizarem elementos que apoiam a avaliação indireta, assim como avaliar a percepção dos usuários quanto à prioridade do preenchimento dos elementos de qualidade por meio de análise multicritério. Outra possibilidade de estudo é a combinação da abordagem AHP com métodos estatísticos de analise multivariada para analisar os elementos de qualidade em relação ao tipo de respondente, afim de verificar se os valores de consistência são validados.

\section{Agradecimentos}

Aos profissionais e estudantes no Brasil e no exterior que gentilmente divulgaram e responderam o questionário que embasou este trabalho.

\section{Contribuição dos Autores}

A conceptualização, a metodologia e a curadoria dos dados foram contribuições do autor Ivanildo. A análise formal, a investigação, a validação, a visualização e a redação foram realizadas por ambos autores.

\section{Conflitos de Interesse}

Os autores declaram que não há conflito de interesse.

\section{Referências}

ARIZA-LÓPEZ, F. J.; GONZÁLEZ, P. B.; PAU, J. M.; TORRES, A. Z.; PASCUAL, A. F. R.; VERGARA, G. M.; BALBOA, J. L. G. Geospatial data quality (ISO 19157-1): evolve or perish. Revista Cartográfica, v. 100, n. 1, p. 129-154, Jan 2020. DOI. https://doi.org/10.35424/rcarto.i100.692

BARBOSA, I.; CASANOVA, M. A. Trust Indicator for Decisions Based on Geospatial Data. In: BRAZILIAN SIMPOSIUM OF GEOINFORMATICS - GEOINFO, 12, 2011, Campos do Jordão. Proceedings... São José dos Campos: INPE, 2011. p 49-60. 2011.

COMBER, A. J.; FISHER, P. F.; HARVEY, F.; GAHEGAN, M.; WADSWORTH, R. A. Using metadata to link uncertainty and data quality assessments. In: RIEDL, A., KAINZ, W., ELMES, G. A. Progress in spatial data handling: Proceedings of the 12th International Symposium on Spatial Data Handling, 
Springer, 2006. p. 279-292.

CONCAR, Perfil de Metadados Geoespaciais Brasileiro. Rio de Janeiro, 2010.

DEGROSSI, L. C.; ALBUQUERQUE, J. P.; ROCHA, R. S.; ZIPF, A. A taxonomy of quality assessment methods for volunteered and crowdsourced geographic information, Transactions in GIS, v. 22, n. 2, p. 542-560, Apr 2018. DOI. https://doi.org/10.1111/tgis.12329

DEPARTAMENTO DE CIÊNCIA E TECNOLOGIA - DCT. Especificação Técnica para Controle de Qualidade de Dados Geoespaciais - EB80-N-72.004, 1ª Edição, Brasília, 2016.

DOS SANTOS, P. H.; NEVES, S. M.; SANT'ANNA, D. O.; DE OLIVEIRA, C. H.; CARVALHO, H. D. The Analytic Hierarchy Process Supporting Decision Making For Sustainable Development: An Overview Of Applications, Journal of Cleaner Production, v. 212, n. 3, p. 119-138, Mar 2019. DOI. https://doi.org/10.1016/j.jclepro.2018.11.270

FOGLIARONI, P.; D'ANTONIO, F.; CLEMENTINI, E. Data trustworthiness and user reputation as indicators of VGI quality. Geo-spatial Information Science, v. 21, n. 3, Sep 2018. DOI. https://doi.org/10.1080/10095020.2018.1496556

FORMAN, E. H.; GASS, S. I. The Analytic Hierarchy Process-An Exposition. Operations Research v. 49, n. 4, p. 469-486, Aug 2001. DOI. https://dl.acm.org/doi/10.5555/2777408.2777409

GRÖNROOS, C. Marketing gerenciamento e serviços. $3^{\text {a }}$. ed. Rio de Janeiro: Elsevier, 2009.

HE, L.; YUE, P.; DI, L.; ZHANG, M.; HU, L. Adding Geospatial Data Provenance into SDI-A ServiceOriented Approach, IEEE Journal of Selected Topics in Applied Earth Observations and Remote Sensing, v. 8, n. 2, p. 926-936. Feb. 2015. DOI. https://doi.org/10.1109/JSTARS.2014.2340737.

HOFFMANN, A. S. A percepção da qualidade na prestação de serviços públicos: estudo de caso da Niterói Terminais Rodoviários - NITER. Universidade Estácio de Sá. Rio de Janeiro, 2006.

INSTITUTO BRASILEIRO DE GEOGRAFIA E ESTATÍSTICA - IBGE. Avaliação da qualidade de dados geoespaciais. $2^{\text {a }}$ Edição. Rio de Janeiro, 2019.

INTERNATIONAL ORGANIZATION FOR STANDARDIZATION - ISO, ISO 19115:2003 - Geographic information - Metadata, 2003.

INTERNATIONAL ORGANIZATION FOR STANDARDIZATION - ISO, ISO 19157:2013 - Geographic information - Data quality, 2013.

JØSANG, A.; ISMAIL, R; BOYD, C. A survey of trust and reputation systems for online service provision. Decision Support Systems, v. 43, v. 2, p. 618-644, Mar 2007. DOI. 10.1016/j.dss.2005.05.019

KLEIN, B. D. User Perceptions of Data Quality: Internet and Traditional Text Sources, Journal of Computer Information Systems, v. 41 n. 4, p. 9-15, 2001.

LUSH, V.; BASTIN, L; JO LUMSDEN, J. Geospatial Data Quality Indicators. In: INTERNATIONAL SYMPOSIUM ON SPATIAL ACCURACY ASSESSMENT IN NATURAL RESOURCES AND ENVIRONMENTAL SCIENCES, 10, 2012, Florianópolis. Proceedings... p. 121-126.

MARINS, C. S.; SOUZA, D. S.; BARROS, M. S. O Uso do Método de Análise Hierárquica (AHP) na Tomada de Decisões Gerenciais - um Estudo de Caso. In: SIMPÓSIO BRASILEIRO DE PESQUISA OPERACIONAL: PESQUISA OPERACIONAL NA GESTÃO DO CONHECIMENTO - SBPO, 41, 2009, Porto Seguro. Anais... p. 1778-1788.

MASÓ, J.; BASTIN, L. OGC® Geospatial User Feedback Standard: Conceptual Model. Version 1.0, 2016.

MORERI, K. K.; FAIRBAIRN, D.; JAMES, P. Volunteered geographic information quality assessment using trust and reputation modelling in land administration systems in developing countries. International Journal of Geographical Information Science. v. 32, n. 5, p. 931-959. Jan 2018. DOI. 10.1080/13658816.2017.1409353

PIPINO, L. L.; LEE, Y. W.; WANG, R. Y. Data Quality Assessment. Communications of the ACM. v. 45, n. 4ve, p. 211-218, Apr 2002. DOI. 10.1145/505248.506010. 
ROCHA, E. C.; GOMES, S. H. A. Gestão da qualidade em unidades de informação. Ciência da Informação, v. 22, n. 2, p. 142-152, May 1993.

SAATY, T. L. Priority Setting in Complex Problems. IEEE Transactions On Engineering Management. v. EM-30, n. 3, p. 140-155, Aug 1983. DOI. https://doi.org/10.1109/TEM.1983.6448606

SENARATNE, H.; MOBASHERI, A.; ALI, A. L.; CAPINERI, C.; HAKLAY, M. A review of volunteered geographic information quality assessment methods. International Journal of Geographical Information Science, v. 31, n. 1, p. 139-167, May 2017. DOI. 10.1080/13658816.2016.1189556

SIPAHI, S.; TIMOR, M. The analytic hierarchy process and analytic network process: an overview of applications, Management Decision, v. 48, n. 5, p. 775-808, Jun 2010. DOI. 10.1108/00251741011043920

STRONG, D. M.; LEE, Y. W.; WANG, R. W. Data Quality In Context. Communications of the ACM, v. 40, n. 5, p. 103-110, May 1997. DOI. 10.1145/253769.253804

VAIDYA, O. S.; KUMAR, S. Analytic hierarchy process: An overview of applications, European Journal of Operational Research, n. 169, v. 1, p. 1-29, Feb 2006. DOI. 10.1016/j.ejor.2004.04.028

WENTZ, E. A.; SHIMIZU, M. Measuring Spatial Data Fitness-for-Use through Multiple Criteria Decision Making. Annals of the American Association of Geographers. v. 108, n. 4, p. 1150-1167, Jan 2018. DOI. 10.1080/24694452.2017.1411246

YUE, P.; BAUMANN, P.; BUGBEE, K.; JIANG, L. Towards intelligent GIServices. Earth Science Informatics, v. 8, p. 463-481. Sep 2015. DOI. 10.1007/s12145-015-0229-z

ZIAIMATIN, H.; NILI, A.; BARROS, A. Reducing Consumer Uncertainty: Towards an Ontology for Geospatial User-Centric Metadata, ISPRS International Journal of Geo-Information, v. 9, n. 8: 488, Aug 2020. DOI. 10.3390/ijgi9080488

\section{Biografia do autor principal}

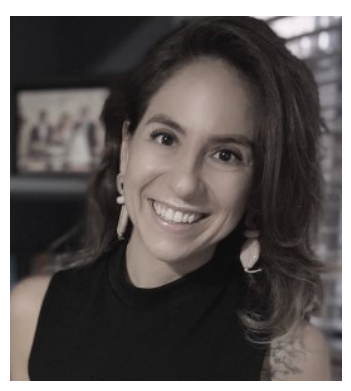

\footnotetext{
Taís Virgínia Gottardo possui graduação em Engenharia de Agrimensura pela Universidade Federal de Viçosa (MG) e mestrado em Engenharia de Defesa pelo Instituto Militar de Engenharia (RJ). Atua como tecnologista no Instituto Brasileiro de Geografia e Estatística no Rio de Janeiro (RJ). Em sua experiência destacam-se os temas Infraestruturas de Dados Espaciais, Metadados Geoespaciais e Qualidade de Dados Geoespaciais. Participou do grupo de trabalho do Comitê de Estruturação da Mapoteca Nacional Digital para atualização da ET-EDGV, do Comitê Técnico da INDE para Dados e Metadados, e da equipe técnica responsável pela atualização do Perfil de Metadados Geoespaciais do Brasil.
}

Esta obra está licenciado com uma Licença Creative Commons Atribuição 4.0 Internacional - CC BY. Esta licença permite que outros distribuam, remixem, adaptem e criem a partir do seu trabalho, mesmo para fins comerciais, desde que lhe atribuam o devido crédito pela criação original. 